\title{
Design of a website for home modifications for older persons with dementia
}

\author{
Helianthe S.M. Kort ${ }^{\mathrm{a}, \mathrm{b}, *}$ and Joost van $\operatorname{Hoof}^{\mathrm{c}}$ \\ ${ }^{a}$ Research Centre for Innovations in Health Care, Faculty of Health Care, Hogeschool Utrecht University of \\ Applied Sciences, Research Group Demand-Driven Care, Utrecht, The Netherlands \\ ${ }^{\mathrm{b}}$ Eindhoven University of Technology, Department of the Built Environment, Unit Building Physics and Services, \\ Eindhoven, The Netherlands \\ ${ }^{\mathrm{c}}$ Centre for Healthcare and Technology, Fontys University of Applied Sciences, Eindhoven, The Netherlands
}

\begin{abstract}
.
BACKGROUND: At present, persons with dementia and their family caregivers in the Netherlands are not adequately supported to modify their dwellings to match their personal needs.

OBJECTIVE: To facilitate aging-in-place for persons with dementia, a website was designed.

METHODS: The website was designed with persons with dementia and their spouses. In consultation sessions existing websites were discussed. Based on this discussion, a demonstration website was created and then discussed with and judged by the participants. Visits to the website were monitored using Google Analytics.

RESULTS: Participants prefer a website that is easy to print. In addition, the navigation menu should have a maximum of three levels, and the website menu should be positioned on the left. Participants dislike the use of meaningless photographs because these do not add any value to the information given.

CONCLUSIONS: Participants prefer a website that is as accessible as reading a book. Some differences are related to culture, such as the participants dislike for the use of English terms. Therefore, preferences or dislikes of items on a website could not be generalized as such. However, the preferences and dislikes may provide useful input for the design process of an appropriate website.
\end{abstract}

Keywords: Older adults, Alzheimer's disease, usability, housing, website, home modifications, adaptations

\section{Introduction}

In the Netherlands, approximately $65 \%$ of the 230,000 older adults with dementia live in the general community. Simultaneously, $40 \%$ of the Dutch housing stock is not sufficiently supportive to enable older adults to live independently [1]. Caring for a person with dementia requires constant vigilance. This need results in significant stress on the family caregivers and often ultimately leads to admission to a nursing

*Corresponding author: Helianthe S.M. Kort, Research Group Demand-Driven Care, Faculty of Health Care, Utrecht University of Applied Sciences, Bolognalaan 101, PO Box 85182 - 3508 AD Utrecht, The Netherlands. E-mail: helianthe.kort@hu.nl. home. Although nursing-home admission cannot always be avoided, it may be postponed by modifying the dwelling and through the use of technology. At present, persons with dementia and their family caregivers lack the means to adapt their dwellings to their needs, because they lack the essential knowledge and do not have access to the correct information. Thus, the creation of dementia-friendly housing by older persons and their caregivers has lagged the need for such housing.

The Dutch Alzheimer's Society ${ }^{1}$ (Alzheimer Nederland) recognizes this problem and has asked the research team to provide information about dementia-

\footnotetext{
${ }^{1}$ http://www.alzheimer-nederland.nl/.
} 
specific environmental adaptations, including home modifications that can support aging-in-place and accessibility for persons with dementia and their family caregivers. The Dutch Alzheimer's Society possesses information about home modifications, but this information is related only to the themes covered by the Dutch Social Support $\mathrm{Act}^{2}$ (Wet maatschappelijke ondersteuning, or Wmo), such as the placement of grab bars in the bathroom or the removal of doorsteps. In the UK, similar web-based sources exist, but they only provide information about assistive technology [2].

In the Netherlands, family caregivers already care for four times as many people as professional caregivers and thus provide the most significant fraction of care [3]. Dementia is the most expensive health problem in the Netherlands. The costs account for $4.7 \%$ of the total national costs for healthcare [4], and the annual costs for care support are on average $€ 617$ per family caregiver [5]. Family care - which is care that is provided to a person with dementia by relatives, particularly spouses and children- not only represents a great societal value, but also a great economic value. Wimo et al. [6] estimated that the worldwide societal cost of family care for dementia was $€ 82.7$ billion in 2005, and that the cost for the European Union (EU) was $€ 26.8$ billion (approximately $€ 4,700$ per person with dementia). These values represent the costs that family caregivers face in terms of expenses and loss of income. Beyond the economic burden, admission to a nursing home has a major impact on family life and spousal relations. Spouses wish to live together and age-in-place for as long as possible. With the appropriate information -and in the case of limited purchasing power, with additional financial means-, they can live as desired.

Internet-based (psycho-educational and coaching) programs for people with dementia and their family caregivers play an increasing role in daily care and in the search for health care information [7-10]. Anderson et al. [9] conclude that for dementia caregivers, the Internet is a convenient source of answers to their many questions and needs. The Internet offers a wide array of resources, including a significant amount of information, advice, and opportunities for support. Considering the demands placed on dementia caregiving and the increasing number of people in society faced with this daunting task, it is in our best interests to provide caregivers with the most accurate, current, and usable on-

\footnotetext{
${ }^{2}$ http://www.rijksoverheid.nl/onderwerpen/wet-maatschappelijke -ondersteuning-wmo.
}

line information and support. Lewis et al. [10] demonstrated that an Internet-based psycho-educational program can strengthen family caregivers' confidence in caring for persons with dementia. In this study, we describe the creation of a website to offer information about home modifications for older adults with dementia and their family caregivers.

\section{Research design and methods}

The website for environmental modifications for older adults with dementia was developed through a combination of literature research, consultation rounds with end-users, and distribution of a set of questions.

\subsection{Literature research}

The content on the website is based on the literature regarding environmental interventions, home modifications, and design of the physical indoor environment and related building services [11-17]. The environmental interventions in this study can be identified as object modification, task simplification, assistive devices, or home modification, following Gitlin and Corcoran [18] (Fig. 1). Based on this categorization, the website comprises four categories: interior design, technology and devices, aspects of the indoor environment, and architectural modifications. This layout is used for all living spaces in a dwelling.

\subsection{Consultation rounds}

A series of consultation rounds was conducted to assess the desires and expectations of persons with dementia and their family caregivers. All potential participants had received an e-bulletin with information about the purpose of the project. This e-bulletin was distributed by the Dutch Alzheimer's Society and was published on their website. An invitation to participate in the consultation rounds was sent by the Dutch Alzheimer's Society by e-mail to the coordinators of several Alzheimer's Cafes in the Province of Utrecht. The participants were potential end-users of the website under construction, and were considered experts in their own field: coping with dementia with respect to aging-in-place. The recruitment of participants, who consented to participate, was performed digitally. The participants were active as volunteers in several working groups of the Dutch Alzheimer's Society. The participants were three couples in which the husbands had 


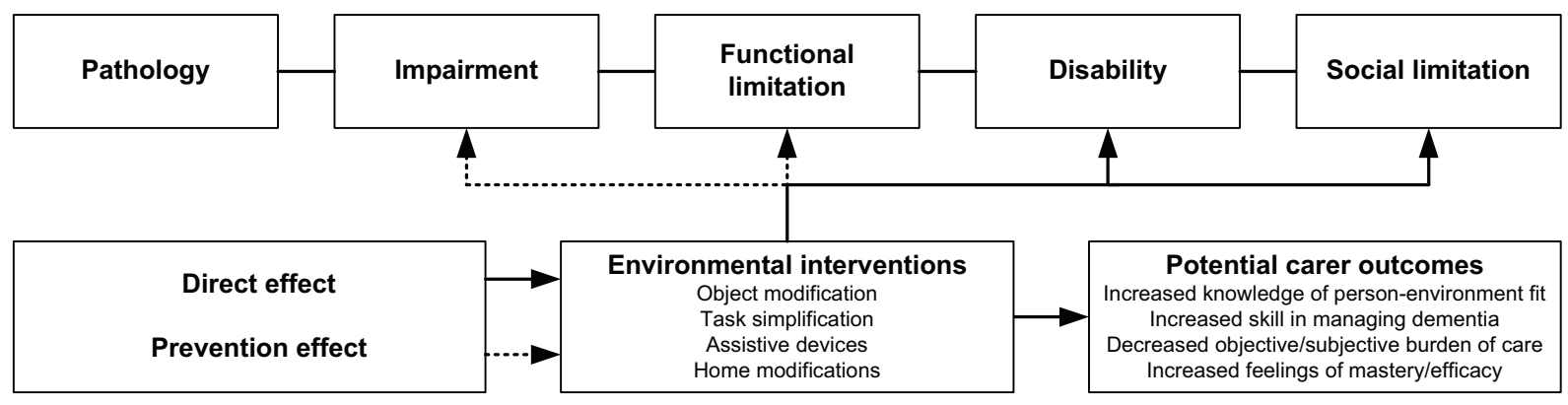

Fig. 1. Disablement model, role of home environmental interventions, and impact on caregivers. Taken and adapted from Gitlin and Corcoran [18].

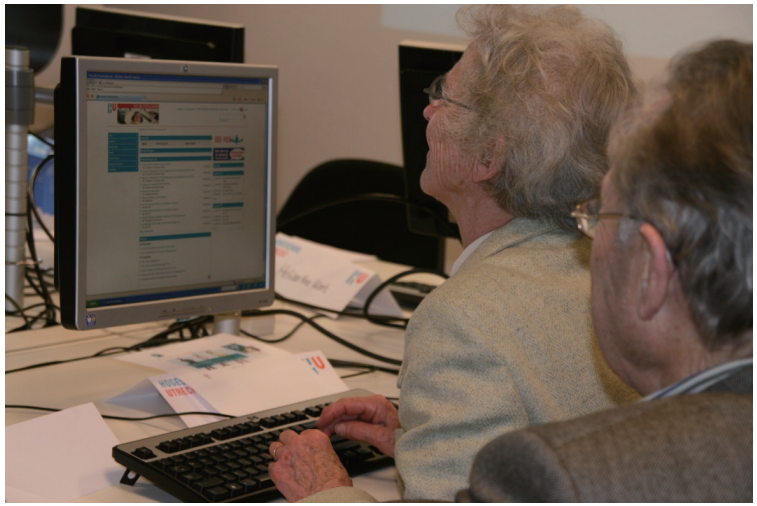

Fig. 2. Participants commenting on the usefulness of existing websites. (Colours are visible in the online version of the article; http:// dx.doi.org/10.3233/TAD-140399)

early dementia (probable Alzheimer's disease). The skills of the participants were such that they could join the consultation rounds. All couples lived independently in their own homes.

Three consultation rounds were scheduled. The first consultation was held on March $25^{\text {th }} 2010$, the second was held on April 22 $2^{\text {nd }} 2010$, and the third was scheduled for June $24^{\text {th }} 2010$. In Session 1, four older adults aged 65 and older participated, and in Session 2, six older adults aged 65 and older participated. A third consultation round was scheduled to gather feedback about the developed demonstration version of the website. All participants had a personal computer (PC) at home and access to the Internet. One couple was novice PC users. The other couples used PCs on a daily basis. The female participants were the ones who used the PC at home and read the information on the Internet for their spouses. The webpages were printed such that the text could be read again after using the PCs.

The consultation rounds were facilitated by members of the research team and were held in one of the faculty's multimedia rooms with access to the Internet. A coordinator of one of the Alzheimer's Cafes at-

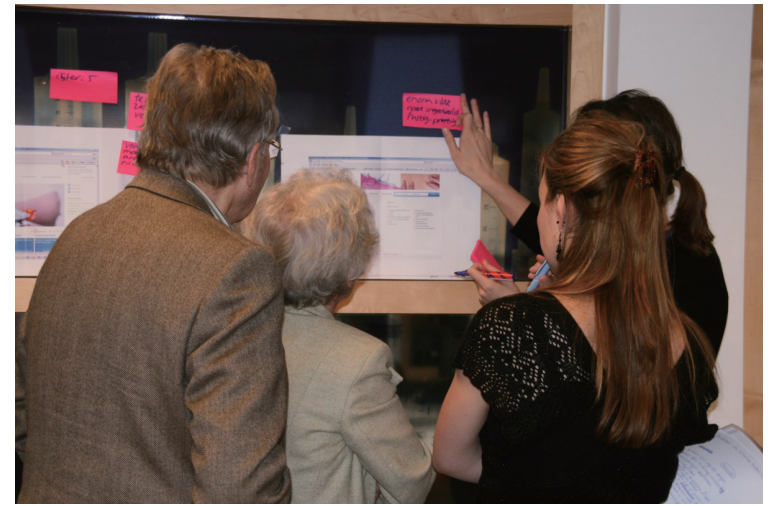

Fig. 3. Providing feedback about existing websites. (Colours are visible in the online version of the article; http://dx.doi.org/10.3233/ TAD-140399)

tended the two consultation rounds. Each consultation round started with an explanation of the purpose of the session. The primary author served as the facilitator. The members of the research team observed the participants, took notes, and if necessary, asked the participants to clarify their answers, feelings or attitudes. Each session lasted approximately 1.5 hours, with a 15-minute break in between the sessions.

The first consultation round aimed to investigate the participants' perspectives on websites. This session included questions about the design, menu, colors used, and ease of finding the information needed. First, the participants were asked to look at and comment on screen shots of several websites (Figs 2 and 3). In addition, the participants were invited to search for websites on the Internet. Notes and observations from this first session were used to develop the topics of the second session. Therefore, during the second consultation round, we focused on how participants search for information about dementia-friendly housing and which keywords they use in this search. This session included questions such as the following: (i) Which issues are of interest? (ii) Is there a differ- 


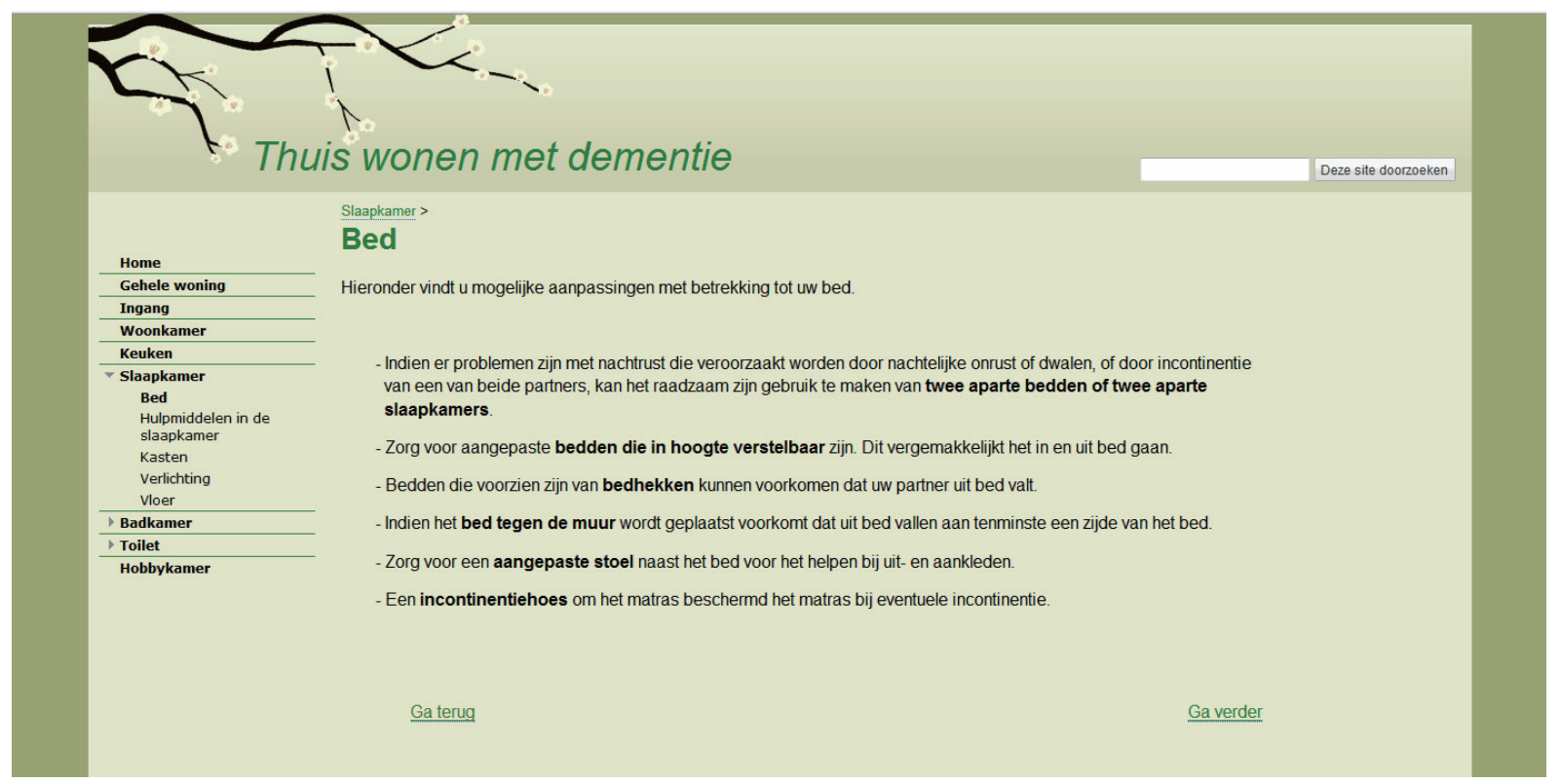

Fig. 4. The preliminary screen-shot based on literature research and the outcomes of the first consultation round, which were used for the discussions with participants. (Colours are visible in the online version of the article; http://dx.doi.org/10.3233/TAD-140399)

ence between long and short uniform resource locators (URLs)? and (iii) Which of the following arrangements for websites is preferred: by (instrumental) activities of daily living ((I)ADL), problem, room, or some combination thereof? In this session, the participants were also asked which URL they would prefer for a website about dementia-friendly housing. The participants discussed several types of website screen shots that were specially made for this session and based upon the results from the first session (Fig. 4). Prior to the third consultation round, a written-consultation round was held to receive feedback about the developed demonstration website for dementia-friendly housing. This demonstration website was developed using the functionalities for creating a website offered by iGoogle. The intention was also that participants would use the demonstration website at home. The themes discussed in the third meeting, were based on those that emerged in the first and second consultation rounds, but focused only on those that were related to the developed demonstration website. The requirements for the development of a demonstration website already met the necessary requirements for web accessibility as specified by the Dutch government [19]. Moreover, work by other researchers regarding websites for older people, the digital provision of in-home assessments for home modification services, and communication practices for people with dementia were consulted [20-23].

\subsection{Set of questions for the users}

Six weeks prior to the official introduction of the website, a set of questions was electronically distributed to the participants in the consultation groups. Furthermore, four months after the official introduction of the website, the set of questions was sent to all participants in the consultation groups and to the participants who were present at the official introduction of the website. In total, 20 people responded to the first set of questions, and 12 people responded to the second set of questions, which was sent after four months. The first set of questions consisted of five parts: Part 1 included general personal data, Part 2 referred to the impressions that the user has about the website, Part 3 was an assignment to search for solutions for wandering in the case of dementia, Part 4 included closed questions scored on a seven-point Likert scale according to the USE questionnaire for measuring usability [24], and Part 5 offered room for remarks. The questionnaires were constructed as seven-point Likert rating scales. Users were asked to rate agreement with the statements, ranging from strongly disagree (1) to strongly agree (7). The results from this first set were used to adapt the website.

The second set of questions consisted of only one part and was intended to evaluate how the website was being used four months after being published on the Internet. The questions were based on Krout's "Seven 
'A's", which are considered key elements for community support [25]. One year after the official introduction of the website, we again analyzed the results from Google Analytics to determine whether the website was still being used.

\section{Results}

In the following section, the results of the consultation rounds, including the set of questions and Google Analytics data, are presented.

\subsection{Consultation rounds}

The participants' expectations were that the website would be a tool for supplying information about environmental modifications and, would ideally provide them with quick access to the appropriate information. They expected to receive information about the possibilities for environmental modifications within the context of the Dutch Social Support Act. Participants would like to be supported and advised on how to modify their home environment from the onset of the dementia process onwards. As native Dutch speakers, they disliked the use of English terminology (Table 1). Bottlenecks that were experienced included the following: (1) information about home-based environmental modifications for dementia being found in several places, (2) reimbursement policies within the Social Support Act differ from one municipality to another, and (3) the technological devices needed to age-inplace often being too complicated to use. The participants' comments about the selected screen shots of websites for older users and their favorite websites, which the participants selected themselves, are summarized in Table 1.

The second session delivered additional information beyond that already yielded by the first session. The participants preferred the use of one color and formal language on the website. The web text should be understood by a layman. The participants disliked closing pop-up menus on a page and preferred menus that can stay open. The homepage should clearly indicate what the website is about. Thus the use of 'ambiance' pictures of older persons on the home page or front page was disliked, partly because of their stigmatizing character. The participants also preferred to have the possibility to read about the experiences of other users.

The most important observations made during this session when the participants browsed on the Internet and had to search for keywords were the following. The participants read the text of the search menu and then clicked on the keywords given. The next method of searching involved the participants first browsing an entire menu of a website to determine whether the website had the content they were looking for. In addition, the keywords used in the searches by the participants were solution-oriented.

During the second session, the participants were invited to discuss their experiences with home environmental modifications. They were interested in having information on the website about automated nightlights and being able to adjust the kitchen countertop in a rectangle such that couples could use the countertop together (i.e., using one place for cooking and another place for washing dishes). The height of the worktop must allow the individuals to see into the pots. During the session, the URL of the website was created through discussion with the participants. The URL should include the words 'dementia', 'safety and security', and 'home', because the participants felt that these captured the essence of the website's content. The participants preferred the information on the website to be arranged by room, or by room first and then by activity.

The participants were content with the demonstration website, which they judged on their home PCs. Some remarked that they preferred the use of simple web text on the website. In the third session, the participants provided feedback about the developed demonstration website. The participants were proud of the website, which they referred to as 'theirs'.

\subsection{Set of questions}

All but one respondent to the first set of questions was a family caregiver. One respondent was a staff member of a home organization. For six respondents there was a child or child-in-law relationship. The respondents who were taking care of their spouses were all 65 years old or older. All respondents had at least vocational training. All respondents used the Internet more than twice per week. The first impression of the respondents was that the website was well-organized and instructive. One suggestion was to also use spoken text. All respondents but two completed the assignment. The assignment was easy to perform for seven respondents. For two respondents, the assignment was too difficult. According to the respondents, the website had a logical enumeration, and the design of the website was skillful and convenient. The respondents 
Table 1

Preferences and dislikes of the participants as expressed in the first session

\begin{tabular}{ll}
\hline Preferences & Dislikes \\
\hline Website menu on the left side of the page & Website menu at the top of the page \\
Website menu that is easy to navigate & Use of several sub-menus \\
Use of a large font size & Use of a small font size \\
Serene-looking pages & Lively looking pages \\
Use of the buttons onward and retrace & Extensive scroll menus \\
Easy-to-read letters & Use of bold letters \\
Clickable text denoted with underlining & Information (text) too close together \\
White space between sections and use of primary colors & Use of several colors \\
Text written in the active voice & Text written in the passive voice \\
Functional photographs only & Photographs with people \\
Website content that is also of interest for installers and electricians & Pictograms \\
& Use of animations \\
& Clickable pictures \\
& Use of English terms \\
\hline
\end{tabular}

Table 2

The results for the six weeks prior to the official introduction of the website. The scores for the closed questions (expressed on a seven-point Likert scale: strongly disagree (1) - strongly agree (7)) are presented

\begin{tabular}{|c|c|c|c|c|c|c|c|c|c|}
\hline $\begin{array}{c}n=9 \\
\text { respondents }\end{array}$ & $\begin{array}{l}\text { Use of } \\
\text { Bullet } \\
\text { points }\end{array}$ & $\begin{array}{l}\text { Bullet points } \\
\text { give structure } \\
\text { to the text }\end{array}$ & $\begin{array}{l}\text { Ease of } \\
\text { finding } \\
\text { information }\end{array}$ & $\begin{array}{l}\text { Bullet } \\
\text { points } \\
\text { are } \\
\text { legible }\end{array}$ & $\begin{array}{l}\text { All information } \\
\text { can be found about } \\
\text { home modification } \\
\text { for dementia }\end{array}$ & $\begin{array}{l}\text { The design of } \\
\text { the website is } \\
\text { appropriate for } \\
\text { what I want to do }\end{array}$ & $\begin{array}{l}\text { The colors are } \\
\text { appropriate } \\
\text { for the } \\
\text { website }\end{array}$ & $\begin{array}{l}\text { Pictures do } \\
\text { support } \\
\text { the text }\end{array}$ & $\begin{array}{c}\text { Pictures } \\
\text { are not } \\
\text { necessary }\end{array}$ \\
\hline Mean & 6.2 & 6.3 & 5.8 & 5.4 & 4.9 & 5.6 & 3.0 & 5.4 & 1.8 \\
\hline SD & 0.8 & 1.0 & 1.6 & 2.3 & 2.2 & 1.7 & 2.4 & 1.4 & 1.8 \\
\hline
\end{tabular}

Table 3

The results of four months after the official introduction of the website. The scores for the closed questions of the Use questionnaire for the measurement of usability (expressed on a seven-point Likert scale: strongly disagree (1) - strongly agree (7)) are listed

\begin{tabular}{lcccc}
\hline$n=11$ respondents & Usefulness & Ease of use & Ease of learning & Satisfaction \\
\hline Mean & 5.7 & 5.7 & 6.1 & 1.3 \\
SD & 1.2 & 1.0 & 1.3 & 1.8 \\
\hline
\end{tabular}

stated that they lacked information about where to purchase the home modifications and technological solutions, the actual target group of the website, certain safety aspects, and information for atypical dwellings. The use of pictures was appreciated by the respondents (Table 2).

Four months after the official introduction, twelve participants returned the set of questions. In Table 3, the results of the USE questionnaire are given. All but one respondent answered the closed questionnaires. According to the respondents, the usability of the website was good.

\subsection{Website}

This Dutch-language website http://www.thuiswon enmetdementie.nl was officially introduced on November $11^{\text {th }}, 2010$. Figure 5 shows the website's introduction page. The introduction page contains information about the purpose of the website, and allows users to browse information about various living spaces of a home. The website distinguishes between existing homes (retrofitting) and homes that are to be newly designed. The font can be adjusted for persons with impaired vision. There is also a search function available to users. Figures 6 and 7 show some of the information about bathrooms. As mentioned above, the website includes four categories: interior design, technology and devices, aspects of the indoor environment, and architectural modifications (Fig. 6). This layout is used for all living spaces in a dwelling. Figures are included on the website to provide real examples of modifications.

\subsection{Google analytics data}

On November $11^{\text {th }}, 2011$ the website had been available to the public for exactly one year. In this first year, the site was visited more than 13,000 times. More than $80 \%$ of the visitors were new visitors. Less than $20 \%$ of the visitors returned to the website more than once. Approximately $37 \%$ of the visitors consulted only one page: these visitors are referred to as 


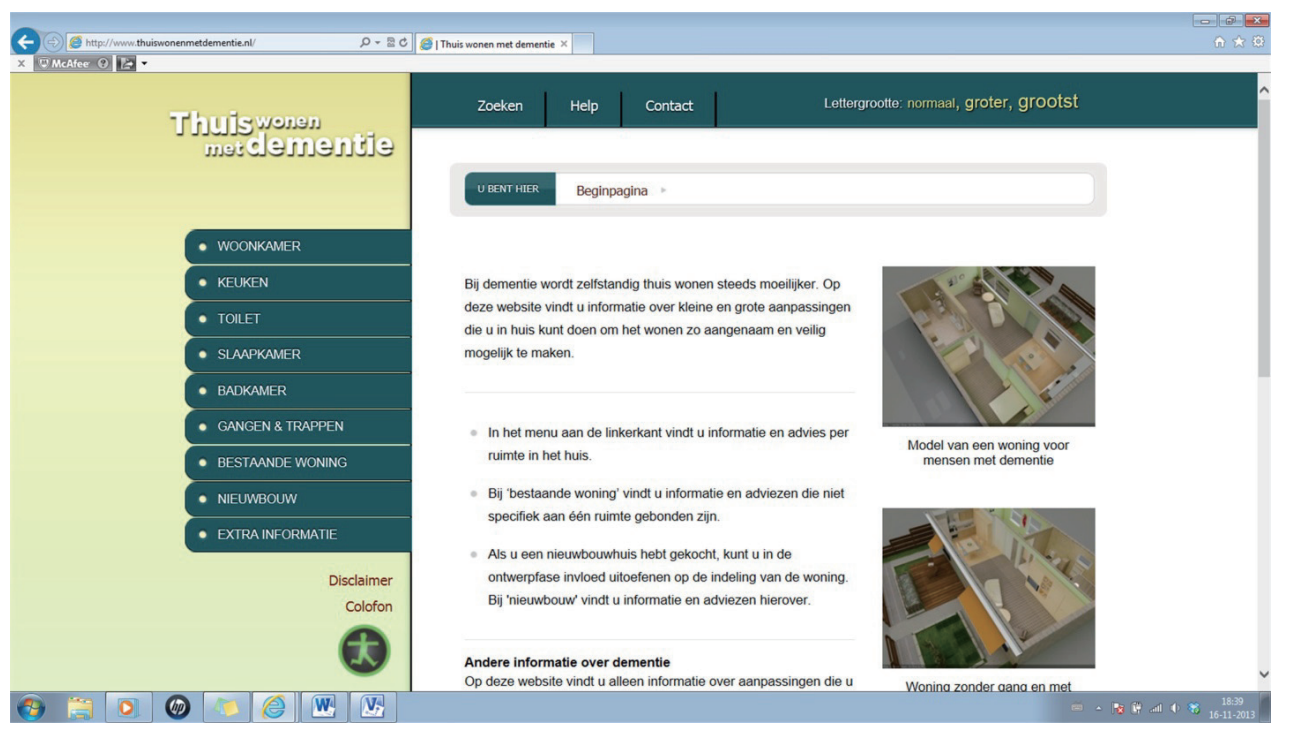

Fig. 5. The website's introduction page. (Colours are visible in the online version of the article; http://dx.doi.org/10.3233/TAD-140399)

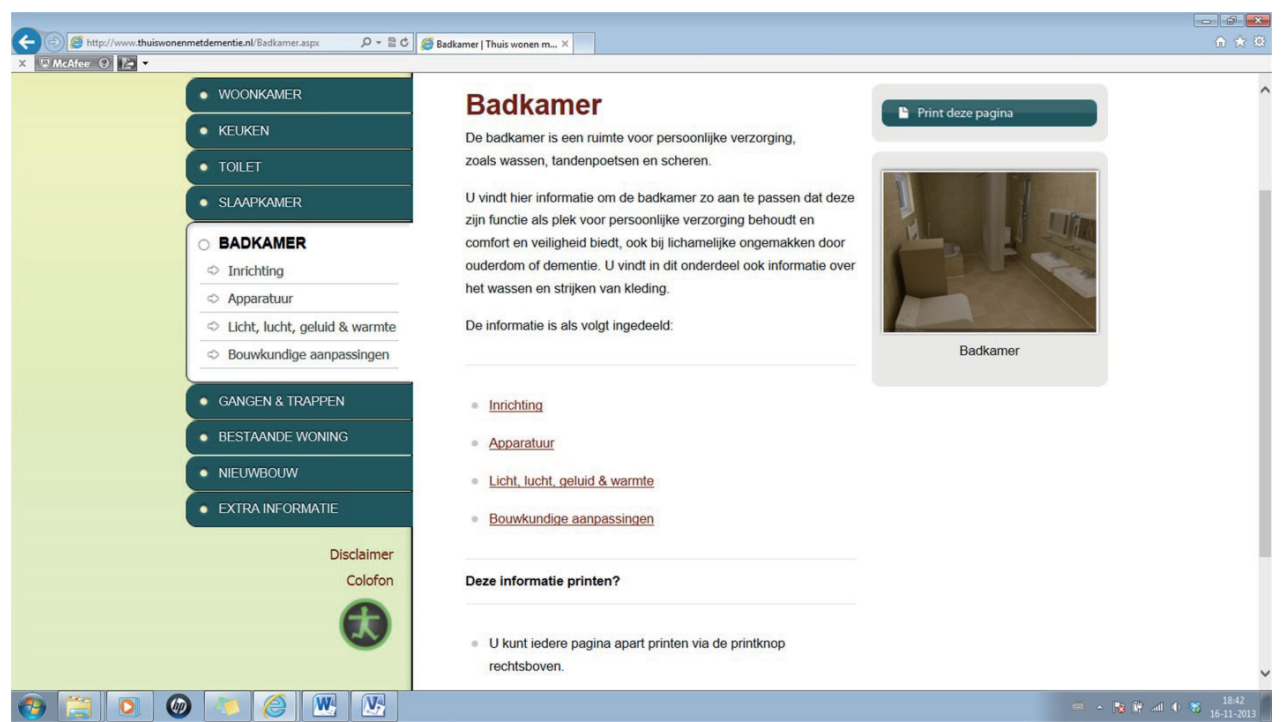

Fig. 6. The webpage that shows the subpages related to the bathrooms. (Colours are visible in the online version of the article; http://dx. doi.org/10.3233/TAD-140399)

accidental visitors. On average the visitors read more than five pages per visit. The highest number of visitors browsed the website on December $9^{\text {th }}, 2010$. The website was mostly read on weekdays. A total of $37 \%$ of the visitors found the website directly, and $19 \%$ found it through a search engine such as Google. Approximately $42 \%$ of the visitors visited the website through a link from another website. The search function on the website was rarely used. The most-read page was the first page on the website, namely the introduction page. The visitors remained there one minute per visit on average.

To date a link to the website is provided on the website of the Dutch Alzheimer's Society. This society also hosts the website.

\section{Conclusions}

Family caregivers of persons with dementia do not have much spare time because of their demanding daily 


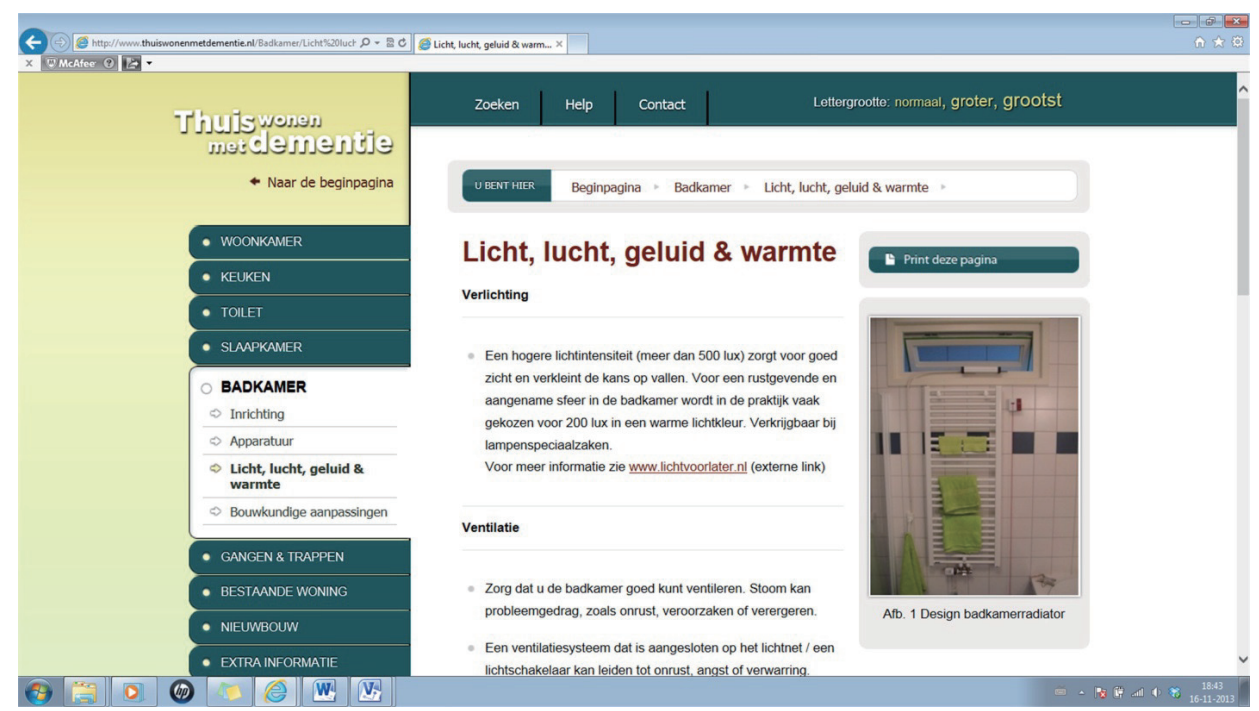

Fig. 7. The webpage that shows the bathroom's subpage about aspects of the physical indoor environment. (Colours are visible in the online version of the article; http://dx.doi.org/10.3233/TAD-140399)

care tasks. These caregivers regularly consult websites to gather information about dementia and possible environmental modifications. Family caregivers are usually spouses, who are still engaged in marital relationships. Their wish is to involve the persons with dementia for as long as possible in the decisions they make based on the information they gathered from the Internet. The participants prefer a website to be as accessible as reading a book. The results were partially in accordance with the results reported in the literature for web design for persons with cognitive disabilities [20,22] and with the checklist for senior-friendly websites $[19,23]$. Some differences are related to culture, such as the participants dislike for the use of English terms. Therefore, preferences or dislikes of items on a website could not be generalized as such. However, the preferences and dislikes may provide useful input for the design process of an appropriate website.

On the website, dementia-friendly home modifications of the living environment are arranged by living space followed by the activity or problem that occurs. Problems are categorized by (I)ADLs, behavior, or cognitive impairment. In the future, the requirements given by the participants could be used for the design of other websites. However, the usability of this website for persons with dementia and their family caregivers needs to be examined. It is important to the participants that caregivers and professionals from the domain of building construction also have access to information about how to design a dwelling in a dementia-friendly way, because these individuals will execute environmental modifications as indicated and desired by the person with dementia or the family caregiver. This information is also of value for professional caregivers and policy makers at the municipal level. Professional caregivers may direct individuals with a lack of knowledge about home modification to relevant web-sources [26]. However, information alone is not sufficient. Instead, training of these professionals is needed to enable persons with dementia to agein-place [16]. Information about environmental modifications contributes, according to Gitlin and Corcoran's model [18], to increased knowledge of personenvironment fit, increased skills at managing dementia, decreased objective/subjective burden of care, and increased feelings of mastery/efficacy (Fig. 1). Furthermore, environmental modifications are needed to support the activities of persons with dementia and their family caregivers [16].

The website was still being visited after one year. Most visitors found the website directly or through a hyperlink on the website of the Dutch Alzheimer's Society. As with any website, it is necessary to ask whether the approach used in this experiment has met the stated goal, which was to inform families with dementia, care professionals and professionals from the domain of building construction and design, and help them with decision making. Further study to examine the usefulness of the designed website is planned.

An earlier study demonstrated that older adults with cognitive impairments (at an early stage) are capable of providing feedback on the design and use of assistive 
technologies [27]. The results of this report concern the design and use of the website. This design process was executed in a single experiment. Therefore, the findings should be interpreted with caution because, the context of the study (housing in the Netherlands, for example) and the small sample number of participants in the consultation rounds may not be generalizable for application in other contexts and countries. The design process reflects the needs of a small group of older people with dementia and their spouses from a Dutch perspective. Nevertheless, the procedure followed in this study may help future developers of websites that have persons with dementia and their spouses as the primary intended audience.

\section{Acknowledgements}

We express our gratitude to the participants in the consultation rounds and the following members of the Dutch Alzheimer's Society (Alzheimer Nederland): Marco Blom, Director of Research and Policy; Herman Post, Head of Communication. From Vilans: Nienke Blijham, project leader; Marion Keizer, Yvonne de Jong and Dorine van den Brandhof, website designers. We are also grateful to the following individuals from Utrecht University of Applied Sciences (Hogeschool Utrecht): Sonja Barends, project manager; Wil Coenen, who provided the Google Analytics data; and Chantal Huisman and Jamie van Dalum, both of whom were Bachelor students in the Faculty of Health Care. This project is part of the Zorg(en) voor Morgen/Future Care project from the Taskforce Innovation Region Utrecht, Pieken in de Delta Grant number PID 082028.

\section{References}

[1] de Boer AH (ed) (2006) Rapportage ouderen 2006. Veranderingen in de leefsituatie en levensloop. The Netherlands Institute for Social Research, The Hague, The Netherlands [in Dutch].

[2] Burrow S, Brooks D. Atdementia: An information resource on assistive technologies that help support the independence of people with dementia. Dementia 2012; 11(4) 553-557 doi: $10.1177 / 1471301212437822$

[3] Sadiraj K, Timmermans J, Ras M, de Boer A (2009) De toekomst van de mantelzorg. The Netherlands Institute for Social Research, The Hague, The Netherlands [in Dutch].

[4] Hoekstra J, Poos MJJC (2008) Welke zorg gebruiken patiënten en wat zijn de kosten? In: Volksgezondheid Toekomst Verkenning, Nationaal Kompas Volksgezondheid. National Institute for Public Health and the Environment, Bilthoven, The Netherlands <http://www.nationaalkompas.nl> Nationaal Kompas Volksgezondheid/Ziekte, kwaliteit van leven en sterfte/Ziekten en aandoeningen/Psychische stoornissen/ Dementie [in Dutch].

[5] de Boer AH, Schellingerhout R, Timmermans JM (2003) Mantelzorg in getallen. The Netherlands Institute for Social Research, The Hague, The Netherlands [in Dutch].

[6] Wimo A, Winblad B, Jönsson L. An estimate of the total worldwide societal costs of dementia in 2005. Alzheimer's \& Dementia 2007; 3(2): 81-91 doi: 10.1016/j.jalz.2007.02.001.

[7] Marziali E, Garcia LJ. Dementia caregivers' responses to 2 Internet-based intervention programs. American Journal of Alzheimer's Disease \& Other Dementias 2011; 26(1): 36-43 doi: $10.1177 / 1533317510387586$.

[8] Rentz M, Von Hoene A. Online coaching for caregivers: Using technology to provide support and information. Alzheimer's Care Today 2010; 11(3): 206-209. doi: 10.1097/ ACQ.0b013e3181ebc878.

[9] Anderson KA, Nikzad-Terhune KA, Gaugler JE. A systematic evaluation of online resources for dementia caregivers. Journal of Consumer Health On the Internet 2009; 13(1): 1-13 doi: $10.1080 / 15398280802674560$.

[10] Lewis ML, Hobday JV, Hepburn KW. Internet-based program for dementia caregivers. American Journal of Alzheimer's Disease \& Other Dementias 2010; 25(8): 674-679 doi: 10.1177/1533317510385812.

[11] van Hoof J, Kort HSM, van Waarde H. Housing and care for older adults with dementia. A European perspective. Journal of Housing and the Built Environment 2009; 24(3): 369-390. doi: 10.1007/s10901-009-9143-3.

[12] van Hoof J, Kort HSM, Hensen JLM, Duijnstee MSH, Rutten PGS. Thermal comfort and integrated building design for older people with dementia. Building and Environment 2010; 45(2): 358-370. doi: 10.1016/j.buildenv.2009.06.013.

[13] van Hoof J, Kort HSM, van Waarde H, Blom MM. Environmental interventions and the design of homes for older adults with dementia: An overview. American Journal of Alzheimer's Disease and Other Dementias 2010; 25(3): 202232. doi: $10.1177 / 1533317509358885$.

[14] van Hoof J, Kort HSM. Supportive living environments: A first concept of a dwelling designed for older adults with dementia. Dementia 2009; 8(2): 293-316. doi: 10.1177/ 1471301209103276.

[15] van Hoof J, Kort HSM, Duijnstee MSH, Rutten PGS, Hensen JLM. The indoor environment and the integrated building design of homes for older people with dementia. Building and Environment 2010; 45(5): 1244-1261. doi: 10.1016/ j.buildenv.2009.11.008

[16] van Hoof, J. (2010) Ageing-in-place: The integrated design of housing facilities for people with dementia. Dissertation. Eindhoven University of Technology, Eindhoven, the Netherlands. ISBN 978-90-386-2326-9.

[17] van Hoof J, Kort HSM, Rutten PGS, Duijnstee MSH. Ageing-in-place with the use of ambient intelligence technology: perspectives of older users. International Journal of Medical Informatics 2011; 80(5): 310-331 doi: 10.1016/ j.ijmedinf.2011.02.010.

[18] Gitlin LN, Corcoran M. Managing dementia at home: The role of home environmental modifications. Topics in Geriatric Rehabilitation 1996; 12(2): 28-39.

[19] Overheid.nl. (2006) Webrichtlijnen Overheid.nl. Richtlijnen voor de toegankelijkheid en duurzaamheid van overheidwebsites, versie 1.2. http://www.advies.overheid.nl [in Dutch].

[20] Demiris G, Finkelstein SM, Speedie SM. Considerations for the design of a web-based clinical monitoring and educational system for elderly patients. Journal of the American 
Medical Informatics Association 2001; 8(5): 468-472 doi: 10.1136/jamia.2001.0080468.

[21] Sanford JA, Jones M, Daviou P, Grogg K, Butterfield T. Using telerehabilitation to identify home modification needs. Assistive Technology 2004; 16(1): 43-53 doi: 10.1080/ 10400435.2004.10132073.

[22] Friedman MG, Bryen DN. Web accessibility design recommendations for people with cognitively disabilities. Technology and Disability 2007; 19(4): 205-211

[23] National Library on Medicine (2002) Making your website senior friendly. A checklist published by the National Institute on Aging and the National Library on Medicine, http://www. nlm.nih.gov/pubs/checklist.pdf.

[24] Lund A (2001). Measuring usability with the USE Questionnaire. Usability Interface: The usability SIG newsletter of the
Society for Technical Communications, 8(2). Retrieved from http://www.stcsig.org/usability/newsletter/0110_measuring_ with use.html.

[25] Krout J. Service awareness among the elderly. Journal of Gerontological Social Work 1985; 9(1): 7-18 doi: 10.1300/ J083V09N01 02.

[26] Cook M, Cook G, Hutchinson F. How to use web-based information to support people with dementia. Nursing Older People 2012, 24(9): 14-20 doi: 10.7748/nop2012.11.24.9.14. c9365.

[27] Pino M (2012) Human Factors and Psychosocial challenges in the design and use of assistive technology for older adults with cognitive impairment. Dissertation. Ecole Pratique Des Hautes Etudes, Paris, France. 